\title{
Expression of aryl hydrocarbon receptor (AHR) and AHR-interacting protein in pituitary adenomas: pathological and clinical implications
}

\begin{abstract}
Marie-Lise Jaffrain-Rea ${ }^{1,2,3}$, Mariolina Angelini ${ }^{1}$, Donatella Gargano ${ }^{1}$, Maria A Tichomirowa ${ }^{4}$, Adrian F Daly ${ }^{4}$, Jean-François Vanbellinghen ${ }^{5}$, Emanuela D'Innocenzo ', Anne Barlier'6, Felice Giangaspero ${ }^{2,7}$, Vincenzo Esposito ${ }^{2}$, Luca Ventura ${ }^{8}$, Antonietta Arcella ${ }^{2}$, Marily Theodoropoulou ${ }^{9}$, Luciana A Naves ${ }^{10}$, Carmen Fajardo ${ }^{11}$, Sabina Zacharieva ${ }^{12}$, Vincent Rohmer ${ }^{13}$, Thierry Brue ${ }^{6}$, Alberto 'Gulino ${ }^{7}$, Giampaolo Cantore', Edoardo Alesse ${ }^{1}$ and Albert Beckers ${ }^{4}$
\end{abstract}

\footnotetext{
${ }^{1}$ Department of Experimental Medicine, University of L'Aquila, via Vetoio, Coppito 2, 67100 L'Aquila, Italy

${ }^{2}$ Neuromed Institute, Istituto di Ricovero e di Ricerca a Carattere Scientifico, Via Atinense 18, 86077 Pozzilli, Italy

${ }^{3}$ Fondazione 'Carlo Ferri' per la prevenzione e la cura dei tumori, via Edmondo Riva 42, 00015 Monterotondo, Italy

${ }^{4}$ Departments of Endocrinology and ${ }^{5}$ Molecular Genetics, Centre Hospitalier Universitaire de Liège, Université de Liège, 4000 Liège, Belgium

${ }^{6}$ Department of Endocrinology, Hôpital de la Timone, Centre de Référence des maladies rares d'origine hypophysaire, Assistance Publique-Hôpitaux de Marseille, and Centre de Recherche en Neurobiologie - Neurophysiologie de Marseille (CRN2M), Unité Mixte de Recherche 6231, Université de la Méditerranée - Université Paul Cézanne - CNRS, 13284 Marseille, France

${ }^{7}$ Department of Experimental Medicine and Pathology, University of Rome 'La Sapienza', Viale dell'Università, 00161 Rome, Italy

${ }^{8}$ Pathology, San Salvatore Hospital, Coppito, 67100 L'Aquila, Italy

${ }^{9}$ Max Planck Institute of Psychiatry, 80804 Munich, Germany

${ }^{10}$ Endocrinology Unit, Faculty of Medicine, University of Brasilia, 70910-900 Brasilia, Brazil

${ }^{11}$ Department of Endocrinology, Hospital Universitario de La Ribera, 46600 Alzira, Spain

${ }^{12}$ Department of Endocrinology, Sofia University, 1303 Sofia, Bulgaria

${ }^{13}$ Endocrinology, Centre Hospitalier Universitaire de Angers, 49033 Angers, France
}

(Correspondence should be addressed to M-L Jaffrain-Rea; Email: jaffrain.ml@libero.it)

\begin{abstract}
Germline mutations of the aryl hydrocarbon receptor (AHR)-interacting protein $(A I P)$ gene confer a predisposition to pituitary adenomas (PA), usually in the setting of familial isolated PA. To provide further insights into the possible role of AIP in pituitary tumour pathogenesis, the expression of AIP and AHR was determined by real-time RT-PCR and/or immunohistochemistry (IHC) in a large series of PA $(n=103)$, including 17 with $A I P$ mutations $\left(A I P^{\text {mut }}\right)$. Variable levels of $A I P$ and $A H R$ transcripts were detected in all $\mathrm{PA}$, with a low $A H R$ expression $(P<0.0001$ versus $A I P)$. Cytoplasmic AIP and AHR were detected by IHC in 84.0 and $38.6 \%$ of PA respectively, and significantly correlated with each other $(P=0.006)$. Nuclear AHR was detected in a minority of PA $(19.7 \%)$. The highest AIP expression was observed in somatotrophinomas and non-secreting (NS) PA, and multivariate analysis in somatotrophinomas showed a significantly lower AIP immunostaining in invasive versus non-invasive cases $(P=0.019)$. AIP expression was commonly low in other secreting PA. AIP immunostaining was abolished in a minority of $A I P^{\text {mut }} \mathrm{PA}$, with a frequent loss of cytoplasmic AHR and no evidence of nuclear AHR. In contrast, AIP overexpression in a subset of NS PA could be accompanied by nuclear AHR immunopositivity. We conclude that down-regulation of AIP and AHR may be involved in the aggressiveness of somatotrophinomas. Overall, IHC is a poorly sensitive tool for the screening of AIP mutations. Data obtained on AHR expression suggest that AHR signalling may be differentially affected according to PA phenotype.
\end{abstract}




\section{Introduction}

Germline mutations of the aryl hydrocarbon receptor (AHR)-interacting protein $(A I P)$ gene confer a predisposition to pituitary adenomas (PA; Vierimaa et al. 2006), usually in the setting of familial isolated PA (FIPA; Daly et al. 2006, 2007, Beckers \& Daly 2007). Because mutations are likely to be inactivating and associated with tumour loss of heterozygosity ( $\mathrm{LOH})$, $A I P$ is viewed as a new pituitary tumour suppressor gene in 11q13 (Vierimaa et al. 2006). Most PA associated with $A I P$ mutations $\left(A I P^{\mathrm{mut}}\right)$ are somatotrophinomas or prolactinomas - although non-secreting (NS) adenomas occur occasionally (Buchbinder et al. 2008). The prevalence of AIP mutations in FIPA is $15 \%$ overall, but reaches $50 \%$ in FIPA kindreds with homogeneous somatotrophinomas (Vierimaa et al. 2006, Daly et al. 2007). AIP ${ }^{\mathrm{mut}} \mathrm{PA}$ occur earlier than their sporadic counterpart and are usually more aggressive (Beckers \& Daly 2007, Daly et al. 2007). Immunohistochemistry (IHC) has shown AIP to be expressed by PA, with loss of AIP staining in $A I P^{\text {mut }}$ tumours being variably appreciated (Vierimaa et al. 2006, Georgitsi et al. 2007, Leontiou et al. 2008). As such, the clinical application of IHC for AIP as a screening tool remains controversial. Germline AIP mutations are very rare in patients with sporadic PA, although they can be encountered in young acromegalics (Barlier et al. 2007, Cazabat et al. 2007, Iwata et al. 2007, Georgitsi et al. 2008a). In addition, although variations in AIP expression among sporadic PA have been recently reported according to their functional phenotype (Leontiou et al. 2008), their potential relationship with tumour-evolutive features has not been investigated. Thus, the possible role of AIP in PA pathogenesis independently of germline mutations is unknown.

The best characterized function of AIP is to stabilize the AHR, or dioxin receptor, in a cytoplasmic core complex involving AIP, AHR and the heat shock protein Hsp90. Upon activation, AHR moves to the nucleus and heterodimerizes with the $\mathrm{Ah}$ receptor nuclear translocator (ARNT) to exert direct transcriptional effects (Petrulis \& Perdew 2002). AHR is widely expressed in endocrine tissues, and dioxin-related compounds are endocrine disruptors (Pitt et al. 2000, Nishimura et al. 2002, Pocar et al. 2005). In vitro exposure to $2,3,7,8$ tetrachlorodibenzo-p-dioxin induces GH and prolactin (PRL) secretion from rainbow trout pituitary cells, in part through AHRmediated transcriptional effects (Elango et al. 2006). AIP generally enhances AHR response to exogenous ligands by increasing its cytoplasmic levels, but nuclear localization of non-ligand-bound AHR can be observed in the absence of AIP (LaPres et al. 2000). This may be relevant to AIP-related tumourigenesis, since endogenous functions of AHR are being increasingly recognized (Barouki et al. 2007, Nguyen \& Bradfield 2008). AHR exerts complex modulatory effects on cell cycle regulation and apoptosis (Marlowe \& Puga 2005), and genetic models have clearly underscored its involvement in normal ontogeny and in tumourigenesis (Gasiewicz et al. 2008). Dioxin is carcinogenic (Popp et al. 2006), and AHR can be overexpressed in human tumours (Harper et al. 2006, Schlezinger et al. 2006). Yet, the effects of dioxin exposure on the incidence of pituitary tumours remain uncertain (Pesatori et al. 2008), and the expression of AHR in the normal human pituitary and in PA has not been reported to date.

We wished to further characterize AIP expression and assess AHR expression and cellular localization in a representative series of PA. We also aimed to further characterize $A I P^{\mathrm{mut}} \mathrm{PA}$ in order to provide new insights into their pathogenesis and possibly help identify patients who could benefit from AIP mutational screening.

\section{Material and methods}

\section{Patients and samples}

A series of 103 PA have been studied for AIP and AHR expression by real-time RT-PCR $(n=66)$ and/or IHC $(n=94)$. There were 46 GH-, 22 PRL-, 7 ACTH-, 2 TSH-secreting and $26 \mathrm{NS}$ adenomas respectively. Unselected sporadic adenomas were operated on for medical reasons at the Neuromed Institute (Italy). Seventeen FIPA samples were collected in 14 FIPA patients who came from eight international centres (Italy, Belgium, France, Brazil, Spain and Bulgaria), out of which 10 PA were operated on in 8 patients with a germline AIP mutation. The study was approved by local ethical committees. Clinical, biological and neuroradiological data, as well as intra-operative findings and pre-operative pharmacological treatment, were systematically recorded. Invasiveness was defined according to pre-operative neuroradiological imaging and intra-operative findings, including macroscopic evidence of dural infiltration. Tumour phenotype was defined on the basis of pre-operative endocrine evaluation and immunohistochemical characterization of hormone secretion. This latter was available in all but two cases and performed with the commercial anti-PRL, anti-GH, anti-FSH, anti-LH, anti-ACTH and anti-TSH antibodies in use in the participating centres (in Italy, polyclonal antibodies from Orthodiagnostic Systems, Raritan, NJ, USA). 
Cell proliferation was evaluated in $77 \mathrm{PA}$ by $\mathrm{Ki}-67$ immunostaining with the monoclonal MIB-1 antibody (DBA Italia srl, Milan, Italy), as previously described (Jaffrain-Rea et al. 2002). Tumours showing microscopic evidence of contamination by normal pituitary fragments were considered for immunohistochemical studies only. In addition, normal human pituitary glands were collected at autopsy in four patients who died from non-endocrine diseases and divided into frozen and formalin-fixed paraffin-embedded fragments, as previously described (Fratticci et al. 2007).

\section{Molecular and genetic analysis}

Methodological details on RT-PCR and real-time RT-PCR protocols are provided in the Supplementary Materials and methods, which can be viewed online at http://erc.endocrinology-journals.org/supplemental/. Briefly, after preliminary, RT-PCR experiments allowed the exclusion of tumour samples with potential contamination with normal pituitary cells according to cell-specific transcription factors' criteria and revealed an almost universal $A I P$ and $A H R$ gene expression; $A I P$ and $A H R$ transcripts were quantified by real-time RT-PCR based on a Taqman methodology and corrected for $\beta$-actin expression. Leukocyte genomic $A I P$ sequencing (gDNA) was performed in 28 patients, as previously described (Daly et al. 2007). Searches for somatic mutations, or $\mathrm{LOH}$ in $A I P^{\text {mut }}$ tumours, were performed by direct sequencing of tumour cDNA and/ or DNA (tDNA) in 35 and 6 cases respectively. Procedures for AIP cDNA sequencing are described in the electronic Supplementary Materials and methods. Overall, the AIP gene status could be determined in 67 cases. Wherever new changes in $A I P$ sequencing were identified, $A I P$ variations were considered as $A I P$ mutations for statistical purposes and their potential biological significance further analysed in the Supplementary Materials and methods and in the Discussion section.

\section{Immunohistochemistry}

Tissue sections were dewaxed in xylene and rehydrated through a descending ethanol series, and antigen retrieval was performed by microwave boiling at $850 \mathrm{~W}$ in citrate buffer $0.1 \mathrm{M}, \mathrm{pH}$ 6.0. Mouse monoclonal antibodies directed against AIP (clone 35-2) and AHR (clone RPT9, referred to as ' $\mathrm{N}-\mathrm{mAb}$ ') were purchased from Novus (Novus Biologicals LLC, Littleton, CO, USA) and both used at a 1:500 dilution, in 94 and 83 PA respectively. A polyclonal rabbit anti-AHR antibody was also used
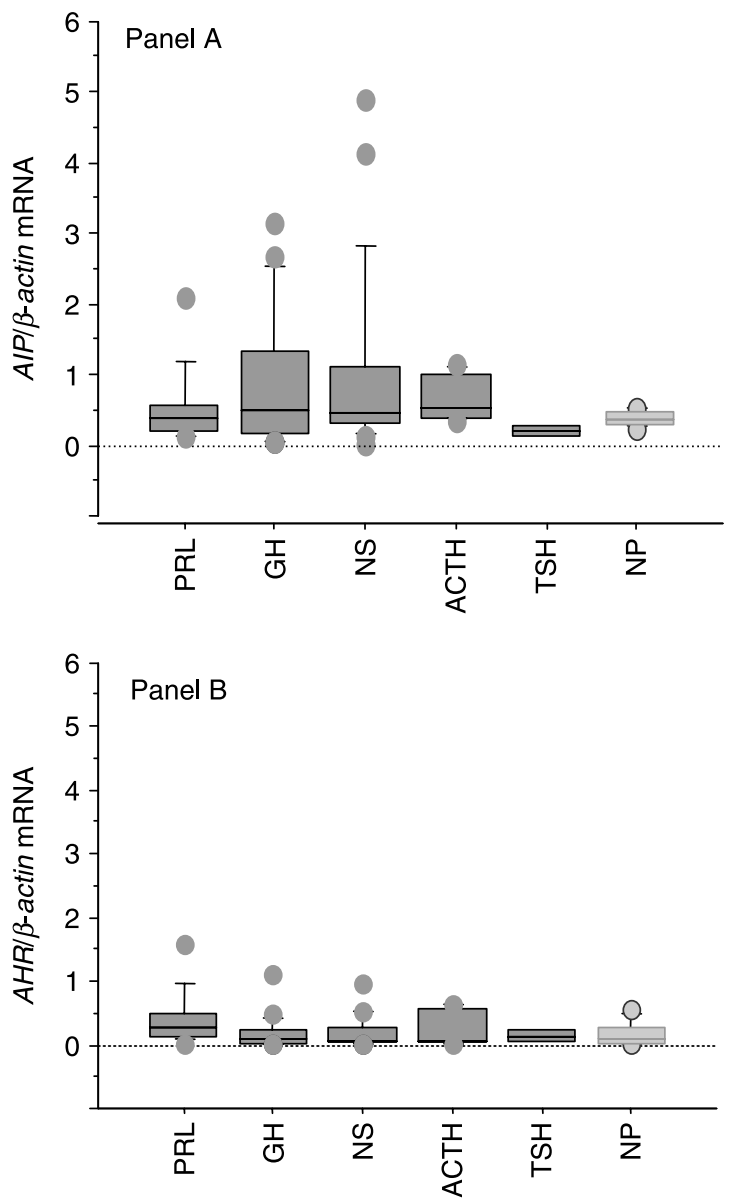

Figure $1 A I P$ and $A H R$ gene expression in pituitary adenomas according to tumour phenotype box plots representing $A I P / \beta$ actin and $A H R / \beta$-actin mRNA ratios in all prolactinomas (PRL), somatotrophinomas $(\mathrm{GH})$, non-secreting adenomas (NS), corticotrophinomas (ACTH), thyrotroph adenomas (TSH) and in normal pituitary samples (NP) are shown in panels $A$ and $B$ respectively (note the different scales used).

in $61 \mathrm{PA}$ (17 PRL-, $21 \mathrm{GH}-, 3 \mathrm{ACTH}-$ secreting and 20 NS respectively) at a 1:50 dilution (sc-5579, referred to as 'C-pAb', Santa Cruz Biotechnology, Santa Cruz, CA, USA). This antibody proved to be more sensitive than the $\mathrm{N}-\mathrm{mAb}$ in the detection of nuclear AHR in positive control sections (human invasive breast cancer samples and rat liver), and cytoplasmic background could be reduced by introducing a further blocking step with $5 \%$ milk in PBS. IHC was performed with a multilink biotinylated antibody and the avidin-biotin peroxidase system according to the manufacturer's instructions $(\mathrm{LSAB}+$ kit, DAKO Cytomation, Milan, Italy). Negative controls were performed omitting the primary antibody. Topographical localization of AIPexpressing cells in normal pituitaries was performed 
Table 1 Aryl hydrocarbon receptor-interacting protein (AIP) expression in the whole series of pituitary adenomas (PA) according to patients and tumours characteristics

\begin{tabular}{|c|c|c|c|c|c|c|c|c|c|c|c|c|c|}
\hline \multirow[b]{2}{*}{ Phenotype } & \multirow[b]{2}{*}{ All } & \multicolumn{2}{|c|}{ Age (years) } & \multirow[b]{2}{*}{$\boldsymbol{P}$} & \multicolumn{2}{|c|}{ Pre-operative treatment } & \multirow[b]{2}{*}{$\boldsymbol{P}$} & \multicolumn{2}{|c|}{ Invasiveness } & \multirow[b]{2}{*}{$P$} & \multicolumn{2}{|c|}{ SSE } & \multirow[b]{2}{*}{$\boldsymbol{P}$} \\
\hline & & $<\mathbf{3 0}$ & $\geq \mathbf{3 0}$ & & Treated & Untreated & & Invasive & Non-Invasive & & Present & Absent & \\
\hline \multicolumn{14}{|l|}{ All PA } \\
\hline $\begin{array}{l}\text { AIP/ } \beta \text {-actin } \\
\text { mRNA (66) }\end{array}$ & $0.8 \pm 0.9$ & $0.3 \pm 0.4$ & $0.9 \pm 1.0$ & 0.015 & & $\mathrm{~N} / \mathrm{A}$ & - & $0.5 \pm 0.7$ & $1.0 \pm 1.0$ & 0.0197 & $0.7 \pm 0.5$ & $0.9 \pm 1.1$ & NS \\
\hline $\begin{array}{l}\text { AIP staining } \\
(94)\end{array}$ & $\begin{array}{l}37 / 94 \\
39.4 \%\end{array}$ & $\begin{array}{l}11 / 32 \\
34.4 \%\end{array}$ & $\begin{array}{l}26 / 62 \\
41.9 \%\end{array}$ & NS & & & - & $\begin{array}{l}14 / 52 \\
26.4 \%\end{array}$ & $\begin{array}{l}22 / 41 \\
53.6 \%\end{array}$ & 0.0090 & $\begin{array}{l}20 / 63 \\
31.7 \%\end{array}$ & $\begin{array}{l}17 / 31 \\
54.8 \%\end{array}$ & 0.031 \\
\hline \multicolumn{14}{|l|}{ GH-secreting } \\
\hline $\begin{array}{l}\text { AIP/ } \beta \text {-actin } \\
\text { mRNA (20) }\end{array}$ & $0.9 \pm 0.9$ & $0.5 \pm 0.6$ & $1.0 \pm 1.0$ & NS & $0.8 \pm 0.9$ & $1.0 \pm 1.0$ & NS & $0.3 \pm 0.2$ & $1.1 \pm 1.0$ & 0.039 & $0.8 \pm 0.6$ & $0.9 \pm 1.1$ & NS \\
\hline $\begin{array}{l}\text { AIP staining } \\
(44)\end{array}$ & $\begin{array}{l}23 / 44 \\
52.3 \%\end{array}$ & $\begin{array}{l}9 / 19 \\
47.4 \%\end{array}$ & $\begin{array}{l}14 / 25 \\
56.0 \%\end{array}$ & NS & $\begin{array}{l}12 / 19 \\
63.1 \%\end{array}$ & $\begin{array}{l}11 / 25 \\
41.7 \%\end{array}$ & NS & $\begin{array}{l}6 / 22 \\
27.3 \%\end{array}$ & $\begin{array}{l}17 / 22 \\
77.3 \%\end{array}$ & 0.0009 & $\begin{array}{l}8 / 25 \\
32.0 \%\end{array}$ & $\begin{array}{l}15 / 19 \\
77.7 \%\end{array}$ & 0.002 \\
\hline \multicolumn{14}{|l|}{ PRL-secreting } \\
\hline $\begin{array}{l}\text { AIP/ } \beta \text {-actin } \\
\text { mRNA (12) }\end{array}$ & $0.5 \pm 0.5$ & $0.1 \pm 0.1$ & $0.6 \pm 0.5$ & NS & $0.3 \pm 0.3$ & $0.6 \pm 0.7$ & NS & $0.4 \pm 0.3$ & $1.0 \pm 0.9$ & NS & $0.5 \pm 0.5$ & - & NS \\
\hline $\begin{array}{l}\text { AIP staining } \\
(21)\end{array}$ & $\begin{array}{l}3 / 21 \\
14.3 \%\end{array}$ & $\begin{array}{l}1 / 8 \\
12.5 \%\end{array}$ & $\begin{array}{l}2 / 13 \\
15.4 \%\end{array}$ & NS & $\begin{array}{l}1 / 7 \\
14.3 \%\end{array}$ & $\begin{array}{l}2 / 14 \\
14.3 \%\end{array}$ & NS & $\begin{array}{l}3 / 15 \\
20.0 \%\end{array}$ & $\begin{array}{l}0 / 6 \\
-\end{array}$ & NS & $\begin{array}{l}3 / 16 \\
18.7 \%\end{array}$ & $\begin{array}{l}0 / 5 \\
-\end{array}$ & NS \\
\hline \multicolumn{14}{|l|}{ Non-secreting } \\
\hline $\begin{array}{l}\text { AIP/ } / \beta \text {-actin } \\
\text { mRNA (25) }\end{array}$ & $1.0 \pm 1.3$ & $0.3 \pm 0.1$ & $1.0 \pm 1.3$ & NS & & $\mathrm{N} / \mathrm{A}$ & - & $0.7 \pm 1.0$ & $1.0 \pm 1.0$ & NS & $1.0 \pm 1.03$ & 0.6 & - \\
\hline $\begin{array}{l}\text { AIP staining } \\
(21)\end{array}$ & $\begin{array}{l}9 / 21 \\
42.8 \%\end{array}$ & $\begin{array}{l}1 / 3 \\
33.3 \%\end{array}$ & $\begin{array}{l}8 / 17 \\
47.0 \%\end{array}$ & NS & & & - & $\begin{array}{l}5 / 14 \\
35.7 \%\end{array}$ & $\begin{array}{l}3 / 6 \\
50.0 \%\end{array}$ & NS & $\begin{array}{l}9 / 19 \\
47.4 \%\end{array}$ & $\begin{array}{l}0 / 1 \\
-\end{array}$ & NS \\
\hline \multicolumn{14}{|l|}{ ACTH-secreting } \\
\hline $\begin{array}{l}\text { AIP/ } \beta \text {-actin } \\
\text { mRNA (7) }\end{array}$ & $0.7 \pm 0.3$ & 0.4 & $0.7 \pm 0.3$ & - & & $\mathrm{N} / \mathrm{A}$ & - & 0.4 & $0.7 \pm 0.3$ & - & $0.4 \pm 0.1$ & $0.8 \pm 0.3$ & NS \\
\hline AIP staining (6) & $\begin{array}{l}1 / 6 \\
16.7 \%\end{array}$ & $\begin{array}{l}0 / 1 \\
-\end{array}$ & $\begin{array}{l}1 / 5 \\
20.0 \%\end{array}$ & - & & & - & $\begin{array}{l}0 / 1 \\
-\end{array}$ & $\begin{array}{l}1 / 5 \\
20.0 \%\end{array}$ & - & $\begin{array}{l}0 / 2 \\
-\end{array}$ & $\begin{array}{l}1 / 4 \\
25.0 \%\end{array}$ & NS \\
\hline \multicolumn{14}{|l|}{ TSH-secreting } \\
\hline $\begin{array}{l}\text { AIP/ } \beta \text {-actin } \\
\text { mRNA (2) }\end{array}$ & $0.2 \pm 0.1$ & 0.3 & 0.1 & - & $0.2 \pm 0.1$ & - & - & - & $0.2 \pm 0.1$ & - & - & $0.2 \pm 0.1$ & - \\
\hline AIP staining (2) & $\begin{array}{l}0 / 2 \\
-\end{array}$ & $\begin{array}{l}0 / 1 \\
-\end{array}$ & $\begin{array}{l}0 / 1 \\
-\end{array}$ & & $\begin{array}{l}0 / 2 \\
-\end{array}$ & - & - & - & $\begin{array}{l}0 / 2 \\
-\end{array}$ & & - & $0 / 2$ & - \\
\hline
\end{tabular}

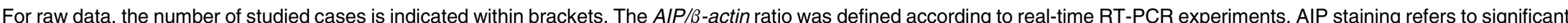

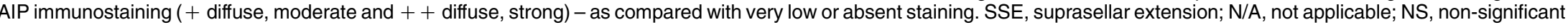
data. 

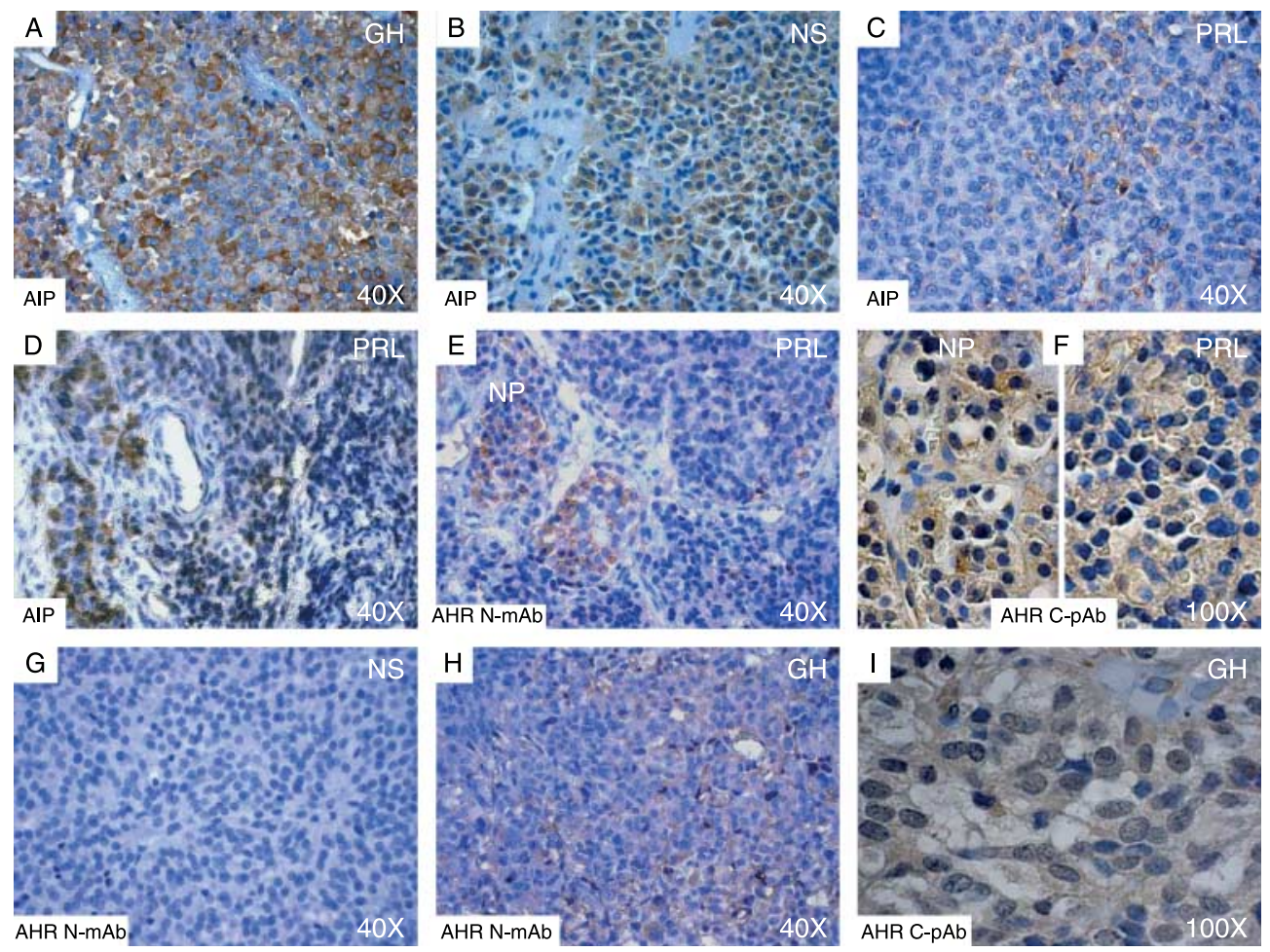

Figure 2 AIP and AHR immunostaining in pituitary adenomas (PA), excluding AIP ${ }^{\text {mut }}$ PA. Shown are representative examples of AIP and AHR immunostaining in different pituitary adenomas (PA), excluding AIP ${ }^{\text {mut }} \mathrm{PA}$. For each image, the PA endocrine phenotype is indicated in the upper right corner, the corresponding antibody in the bottom left corner and magnification in the bottom right corner respectively. AIP immunostaining was quoted ++ in a somatotrophinoma, + in a non-secreting PA and $+/-$ in a prolactinoma (A, B and C respectively). An example of microprolactinoma displaying AIP and AHR down-regulation (quoted $+/-$ ) as compared with the adjacent normal pituitary (indicated as NP) is shown in D and E respectively; nuclear AHR staining in this case was observed in the normal pituitary, but not in adenoma cells (F). Most PA had no or weak AHR immunoreactivity ( $G$ and $H$ respectively), a few cases displaying nuclear immunostaining, including a non-secreting FIPA without AIP mutation (I).

using pre-diluted mouse mAbs for pituitary hormones (DAKO Cytomation). Semi-quantitative analysis of cytoplasmic AIP and AHR immunostaining was performed at $20 \times$ and $40 \times$ magnifications and semiquantitatively scored as follows: - (negative); $+/-$ (weak immunostaining and/or scattered positive cells); + (diffuse, moderate immunostaining); ++ (diffuse, strong immunostaining). In the presence of heterogeneous staining, the areas obtaining the highest score were considered for statistical purposes. Nuclear staining for AHR (C-pAb) was further evaluated at high magnification $(100 \times)$ in all cases. A double step immunohistochemical study was also performed as previously described (Fratticci et al. 2007) to first detect cytoplasmic AIP or the pituitary hormones GH, PRL, ACTH and FSH respectively using 3-3'-diaminobenzidine (DAB) as a chromogen, followed by a second step for the detection of nuclear AHR (C-pAb) using Novored as a chromogen (Vector, DBA Italia), introducing a further blocking step with milk as indicated hitherto. Photographs of slides were taken using a Zeiss Axioplan 2 microscope and a Leica DFC 320 digital camera.

\section{Statistical analysis}

All data are expressed in mean \pm s.D. and statistical analyses were performed using Statview 5.01 software for PC (SAS Institute, Cary, NC, USA). Continuous values were analysed by non-parametric analysis, using Mann-Whitney and Kruskal-Wallis test for 2 and $\geq 3$ group comparisons respectively and the Spearman test for correlation studies. Distribution of nominal values was compared by the $\chi^{2}$-test, logistic regression being used for multivariate analysis. For logistic regression and analysis of subgroups, the immunostaining scores for cytoplasmic AIP and AHR were transformed into binary parameters as follows: significant (scores + and ++ ) versus low ( - and $+/-$ ) AIP immunostaining; and 


\begin{tabular}{|c|c|c|c|c|c|c|c|c|c|c|c|c|}
\hline $\begin{array}{l}\text { Patients } \\
\text { surgery }\end{array}$ & $\begin{array}{c}A I P \\
\text { mutation }\end{array}$ & Country & Sex & $\begin{array}{c}\text { Age } \\
\text { (years) }\end{array}$ & Symptoms $^{b}$ & Tumour $^{\mathrm{C}}$ & $\begin{array}{c}\text { Hormone } \\
\text { values at } \\
\text { diagnosis } \\
(\mathrm{ng} / \mathrm{ml})\end{array}$ & $\begin{array}{l}\text { Pre-op } \\
\text { treatment }\end{array}$ & $\begin{array}{c}\text { Pre-op } \\
\text { hormone } \\
\text { values }(\mathrm{ng} / \mathrm{ml})\end{array}$ & $\begin{array}{l}\text { Pituitary } \\
\text { hormones } \\
\text { IHC }\end{array}$ & $\begin{array}{l}\text { AIP } \\
\text { IHC }^{d}\end{array}$ & $\begin{array}{l}\text { AHR } \\
\text { IHC }^{\text {e }}\end{array}$ \\
\hline \multicolumn{13}{|l|}{ Fam $1^{(\mathrm{i}, \mathrm{ii})}$} \\
\hline$\underset{T C}{\text { Fam } 1 \mathrm{~A}}$ & $\mathrm{R} 304 \mathrm{X}$ & Italy & $\mathrm{F}$ & 19 & $\begin{array}{l}\text { Amenorrhoea-galac- } \\
\text { torrhoea, visual } \\
\text { loss, bitemporal } \\
\text { haemianopsia, } \\
\text { weight gain and } \\
\text { hydrocephalus } \\
\text { requiring emer- } \\
\text { gency surgery for } \\
\text { ventricular deri- } \\
\text { vation (VD) }\end{array}$ & $\begin{array}{l}\text { Giant-SSE } \\
\quad(52 \mathrm{~mm}) \\
\text { Inv }+ \text { (CS) }\end{array}$ & $\begin{array}{l}\text { PRL 99, } \\
\text { Post-VD, } \\
\text { GH 15.8, } \\
\text { IGF-I 420, } \\
\text { PRL } 32\end{array}$ & $\begin{array}{l}\text { OCT up to } \\
200 \mu \mathrm{g} \\
\text { t.i.d. CAB } \\
0.5 \mathrm{mg} \\
\times 2 / \mathrm{w}\end{array}$ & $\begin{array}{l}\text { PRL 9.1, } \\
\text { GH 16.0, } \\
\text { IGF } 900\end{array}$ & $\begin{array}{l}\mathrm{GH}, \\
\quad \mathrm{FSH}( \pm), \\
\mathrm{Ki}-67,0.5 \%\end{array}$ & $\begin{array}{l}+/- \\
\text { (scattered } \\
\text { cells }+ \text { ) }\end{array}$ & $\mathrm{C}-\mathrm{N}-$ \\
\hline $\begin{array}{l}\text { Fam 1B } \\
1^{r s t} T S\end{array}$ & R304X & Italy & $\mathrm{F}$ & 21 & $\begin{array}{l}\text { Amenorrhoea, weight } \\
\text { gain, mild acrome- } \\
\text { galy, } \mathrm{DH} 164 \mathrm{~cm} \\
\text { and headache }\end{array}$ & $\begin{array}{l}\text { Giant-SSE } \\
\quad(41 \mathrm{~mm}) \\
\text { Inv }+(\mathrm{CS})\end{array}$ & $\begin{array}{l}\text { GH } 33, \\
\text { IGF-I } 630, \\
\text { PRL } 5\end{array}$ & None & $\begin{array}{l}\text { See values at } \\
\text { diagnosis }\end{array}$ & $\begin{array}{r}\mathrm{GH}, \mathrm{PRL}( \pm), \\
\mathrm{Ki}-67,6.0 \%\end{array}$ & $+1-$ & $C-N$ ND \\
\hline $2^{\circ} T S$ & R304X & Italy & $\mathrm{F}$ & 22 & $\begin{array}{l}\text { Evolutive disease } \\
\text { and pharma- } \\
\text { cological resist- } \\
\text { ance }\end{array}$ & $\begin{array}{l}\text { Ma-SSE } \\
\quad(27 \mathrm{~mm}), \\
\text { Inv }+(\mathrm{CS})\end{array}$ & $\begin{array}{l}\text { Post-TS1 } \\
\text { GH 4.0, } \\
\text { IGF-I 400, } \\
\text { PRL } 7.2\end{array}$ & $\begin{array}{l}\text { LAN } 30 \mathrm{mg} \\
\qquad / 14 \mathrm{~d} . \text { CAB } \\
0.5 \mathrm{mg} \\
\times 2 / \mathrm{w} .\end{array}$ & $\begin{array}{l}\text { GH } 5.8 \\
\text { IGF-I } 598 \\
\text { PRL } 1.3\end{array}$ & $\begin{array}{c}\mathrm{GH}, \mathrm{FSH}, \mathrm{LH} \\
( \pm), \mathrm{Ki}-67 \\
2.7 \%\end{array}$ & $+1-$ & $C-N$ ND \\
\hline $\begin{array}{l}\text { Fam 1C } \\
\text { TS }\end{array}$ & R304X & Italy & M & 8 & Incipient gigantism & $\begin{array}{l}\text { Ma-IS } \\
\quad(12 \mathrm{~mm}), \\
\quad \text { Inv }-\end{array}$ & $\begin{array}{l}\text { GH } 48.2, \\
\text { IGF-I } \\
\text { 1070, } \\
\text { PRL } 11.8\end{array}$ & $\begin{array}{l}\text { OCT-LAR } \\
10 \mathrm{mg} / 28 \mathrm{~d} .\end{array}$ & $\begin{array}{l}\text { GH } 65.9 \\
\text { IGF-I } 1294 \\
\text { PRL } 21.9\end{array}$ & $\begin{array}{l}\mathrm{GH}, \mathrm{Ki}-67 \\
5.0 \%\end{array}$ & $\begin{array}{l}+/- \\
\text { (scattered } \\
\text { cells }+ \text { ) }\end{array}$ & $\mathrm{C}-\mathrm{N}-$ \\
\hline \multicolumn{13}{|l|}{ Fam $2^{(i)}$} \\
\hline$\underset{T S}{\text { Fam } 2 \mathrm{~A}}$ & Q285fs17X & Italy & $M$ & 21 & $\begin{array}{l}\text { Gigantism - DH } \\
208 \mathrm{~cm} \text {, headache } \\
\text { and visual fields' } \\
\text { defects }\end{array}$ & $\begin{array}{l}\text { Ma-SSE } \\
\quad(28 \mathrm{~mm}), \\
\text { Inv }+\end{array}$ & $\begin{array}{c}\mathrm{GH}>30.0 \\
\text { PRL } 7.4 \\
\text { IGF-I N/A }\end{array}$ & None & $\begin{array}{l}\text { See values at } \\
\text { diagnosis }\end{array}$ & $\begin{array}{r}\mathrm{GH}, \mathrm{PRL}( \pm), \\
\mathrm{Ki}-67,0.7 \%\end{array}$ & $+1-$ & $\mathrm{C}-\mathrm{N}-$ \\
\hline $\begin{array}{c}\text { Fam 2B } \\
1^{r s t} T S\end{array}$ & Q285fs17X & Italy & M & 33 & $\begin{array}{l}\text { Acromegaly - DH } \\
185 \mathrm{~cm}\end{array}$ & $\begin{array}{l}\text { Ma-SSE } \\
\quad(30 \mathrm{~mm}) \\
\text { Inv }+(\mathrm{CS})\end{array}$ & $\begin{array}{l}\text { GH } 74.0, \\
\text { IGF-I } 664, \\
\text { PRL } 35.4\end{array}$ & $\begin{array}{l}\text { OCT-LAR } \\
20 \mathrm{mg} / 28 \mathrm{~d} \text {. }\end{array}$ & $\begin{array}{l}\text { GH } 3.5, \\
\text { IGF-I } 414, \\
\text { PRL } 4.4\end{array}$ & $\begin{array}{l}\mathrm{GH}, \mathrm{PRL}, \\
\mathrm{FSH}( \pm) \\
\mathrm{Ki}-67,0 \%\end{array}$ & $\begin{array}{l}+/- \\
\quad \text { (large } \\
\text { areas }-)\end{array}$ & $\mathrm{C}-\mathrm{N}-$ \\
\hline $2^{\text {nd }} T S$ & Q285fs17X & Italy & M & 34 & Evolutive acromegaly & $\begin{array}{l}\text { Ma-IS } \\
\quad(15 \mathrm{~mm}) \\
\text { Inv }+(\mathrm{CS})\end{array}$ & $\begin{array}{l}\text { GH } 6.0, \\
\text { IGF-I } 540 \\
\text { PRL } 7.0\end{array}$ & $\begin{array}{l}\text { OCT-LAR } \\
10 \mathrm{mg} / 28 \mathrm{~d} .\end{array}$ & $\begin{array}{l}\text { GH } 19.6, \\
\text { IGF-I } 449, \\
\text { PRL } 6.7\end{array}$ & $\begin{array}{c}\mathrm{GH}, \mathrm{PRL}( \pm), \\
\mathrm{Ki}-67,0 \%\end{array}$ & - & $\mathrm{C}-$ \\
\hline \multicolumn{13}{|l|}{ Fam $3^{(i)}$} \\
\hline $\begin{array}{l}\text { Fam3A } \\
\text { TS }\end{array}$ & K241E & Belgium & $\mathrm{F}$ & 53 & $\begin{array}{l}\text { Visual loss and } \\
\text { bitemporal } \\
\text { haemianopsia. }\end{array}$ & $\begin{array}{l}\text { Ma-SSE } \\
\quad(30 \mathrm{~mm}) \\
\text { Inv }+\end{array}$ & $\begin{array}{l}\text { PRL 41, } \\
\text { IGF-I } 50\end{array}$ & None & $\begin{array}{l}\text { See values at } \\
\text { diagnosis }\end{array}$ & FSH, LH & + & $\mathrm{C}-\mathrm{N}-$ \\
\hline $\begin{array}{l}\text { Fam 3B } \\
\text { TS }\end{array}$ & K241E & Belgium & M & 53 & Visual loss & $\begin{array}{l}\text { Ma-SSE } \\
\quad(34 \mathrm{~mm}) \\
\text { Inv }+(\mathrm{CS})\end{array}$ & $\begin{array}{l}\text { PRL 2333, } \\
\text { GH } 0.2, \\
\text { IGF-I } 100\end{array}$ & $\begin{array}{l}\text { CAB } 0.5 \mathrm{mg} \\
\times 2 / \mathrm{w} .\end{array}$ & $\begin{array}{l}\text { PRL 12.5, } \\
\text { GH } 0.2\end{array}$ & PRL & - & $C-N N D$ \\
\hline
\end{tabular}




\begin{tabular}{|c|c|c|c|c|c|c|c|c|c|c|c|c|}
\hline $\begin{array}{l}\text { Patients } \\
\text { surgery }^{\mathrm{a}}\end{array}$ & $\begin{array}{c}A I P \\
\text { mutation }\end{array}$ & Country & Sex & $\begin{array}{c}\text { Age } \\
\text { (years) }\end{array}$ & Symptoms ${ }^{b}$ & Tumour $^{\mathrm{c}}$ & $\begin{array}{c}\text { Hormone } \\
\text { values at } \\
\text { diagnosis } \\
(\mathrm{ng} / \mathrm{ml})\end{array}$ & $\begin{array}{l}\text { Pre-op } \\
\text { treatment }\end{array}$ & $\begin{array}{c}\text { Pre-op } \\
\text { hormone } \\
\text { values }(\mathrm{ng} / \mathrm{ml})\end{array}$ & $\begin{array}{c}\text { Pituitary } \\
\text { hormones } \\
\text { IHC }\end{array}$ & $\begin{array}{l}\text { AIP } \\
\text { IHC }^{d}\end{array}$ & $\begin{array}{l}\text { AHR } \\
\text { IHC }^{e}\end{array}$ \\
\hline $\begin{array}{l}\text { Fam } 4^{\text {(iii) }} \\
\text { TS }\end{array}$ & E174fs21X & Brazil & $M$ & 17 & $\begin{array}{l}\text { Gigantism, DH } \\
193 \mathrm{~cm} \text {, headache } \\
\text { and visual fields' } \\
\text { defect }\end{array}$ & $\begin{array}{l}\text { Giant-SSE } \\
(46 \mathrm{~mm}) \\
\text { Inv }+ \text { (CS) }\end{array}$ & $\begin{array}{l}\text { GH } 51 \\
\text { IGF-I } 778, \\
\text { PRL } 50\end{array}$ & None & $\begin{array}{l}\text { See values at } \\
\text { diagnosis }\end{array}$ & $\begin{array}{l}\mathrm{GH}, \mathrm{PRL}, \\
\mathrm{Ki}-67,0 \%\end{array}$ & Het,$++/-$ & $\mathrm{C}+\mathrm{I}-\mathrm{N}-$ \\
\hline $\begin{array}{l}\text { Spor } 1 \\
\text { TS }\end{array}$ & V195A & Brazil & M & 12 & $\begin{array}{l}\text { Visual loss and pre- } \\
\text { puberal, post-oper- } \\
\text { ative resistance to } \\
\text { dopamine-agonists }\end{array}$ & $\begin{array}{l}\text { Giant-SSE } \\
(40 \mathrm{~mm}) \\
\text { Inv }+(\mathrm{CS})\end{array}$ & $\begin{array}{c}\text { PRL } 10561, \\
\text { GH } 0.06, \\
\text { IGF-1 } 147\end{array}$ & None & $\begin{array}{l}\text { See values at } \\
\text { diagnosis }\end{array}$ & $\begin{array}{l}\text { PRL, Ki-67, } \\
\quad 0 \%\end{array}$ & + & $C-N$ ND \\
\hline $\begin{array}{l}\text { Spor } 2 \\
\text { TS }\end{array}$ & A277P & Italy & $M$ & 12 & $\begin{array}{l}\text { Incipient gigantism } \\
\text { and visual defect }\end{array}$ & $\begin{array}{l}\text { Ma-SSE } \\
\quad(27 \mathrm{~mm}) \\
\text { Inv + (CS) }\end{array}$ & $\begin{array}{l}\text { GH } 13.6, \\
\text { IGF-I 530, } \\
\text { PRL } 52.5\end{array}$ & None & $\begin{array}{l}\text { See values at } \\
\text { diagnosis }\end{array}$ & $\begin{array}{c}\mathrm{GH}, \mathrm{PRL}, \mathrm{Ki}- \\
\quad 67,15.0 \%\end{array}$ & $+1-$ & $\mathrm{C}-\mathrm{N}-$ \\
\hline $\begin{array}{l}\text { Spor } 3 \\
\text { TS }\end{array}$ & $\begin{array}{l}\text { IVS3 } \\
\quad \text { c. } 468+ \\
16 G>T\end{array}$ & Italy & $F$ & 15 & $\begin{array}{l}\text { Oligomenorrhoea, } \\
\text { visual field defects } \\
\text { and then pituitary } \\
\text { apoplexy }\end{array}$ & $\begin{array}{l}\text { Ma-SSE } \\
\quad(20 \mathrm{~mm}), \\
\text { Inv + (CS) }\end{array}$ & $\mathrm{N} / \mathrm{A}$ & None & $\mathrm{N} / \mathrm{A}$ & $\begin{array}{l}\mathrm{GH}, \mathrm{Ki}-67 \\
0.5 \%\end{array}$ & $\begin{array}{c}- \text { (in part } \\
\text { necrotic) }\end{array}$ & ND \\
\hline $\begin{array}{l}\text { Spor } 4 \\
\text { TS }\end{array}$ & $\begin{array}{l}\text { IVS3 } \\
\quad \begin{array}{l}\text { c. } 468+ \\
15 \mathrm{C}>\mathrm{T}\end{array}\end{array}$ & $\begin{array}{l}\text { Spain } \\
\text { (Ecuador) }\end{array}$ & $\mathrm{F}$ & 17 & $\begin{array}{l}\text { Acromegaly, tall sta- } \\
\text { ture, headache and } \\
\text { menstrual disturb- } \\
\text { ance }\end{array}$ & $\begin{array}{l}\text { Ma-IS } \\
\quad(13 \mathrm{~mm}), \\
\text { Inv }-\end{array}$ & $\begin{array}{l}\text { GH } 54.8, \\
\text { IGF-I } 635, \\
\text { PRL } \uparrow\end{array}$ & $\begin{array}{l}\text { LAN- } 60 \mathrm{mg} \\
\text { i.m. } / 28 \mathrm{~d} .\end{array}$ & $\mathrm{N} / \mathrm{A}$ & $\begin{array}{l}\text { GH, PRL } \\
\text { FSH, LH, } \\
\text { ACTH }( \pm)\end{array}$ & Het $+/-,-$ & $C+I-N N D$ \\
\hline Spor 5 & Q82fsX7 & Bulgaria & $M$ & 15 & $\begin{array}{l}\text { Gigantism, headache } \\
\text { and hydrocephalus }\end{array}$ & $\begin{array}{l}\text { Giant-SSE } \\
\quad(60 \mathrm{~mm}), \\
\text { Inv }+\end{array}$ & $\mathrm{N} / \mathrm{A}$ & None $(\mathrm{Rx} T)$ & $\begin{array}{l}\text { GH } 42.3, \\
\text { IGF-I } \uparrow, \\
\text { PRL } 60\end{array}$ & $\mathrm{GH}$ & - & $C-N$ ND \\
\hline $\begin{array}{l}\text { Spor } 6 \\
\text { TS }\end{array}$ & $\mathrm{R} 128 \mathrm{H}$ & $\begin{array}{l}\text { Belgium } \\
\text { (Morocco) }\end{array}$ & $M$ & 27 & Acromegaly & $\begin{array}{l}\text { Ma-SSE } \\
\quad(20 \mathrm{~mm}), \\
\text { Inv - }\end{array}$ & $\begin{array}{l}\text { GH } 58.7, \\
\text { IGF-I 909, } \\
\text { PRL N/A }\end{array}$ & $\begin{array}{l}\text { OCT } 100 \mu \mathrm{g} \\
\text { t.i.d. } \\
\text { CAB } \\
0.5 \mathrm{mg} \\
\times 2 / \mathrm{w}\end{array}$ & IGF-I 1090 & $\mathrm{GH}$ & Het $++/+$ & ND \\
\hline $\begin{array}{l}\text { Spor } 7 \\
\text { TS }\end{array}$ & $\begin{array}{l}\text { IVS2 } \\
\quad \text { c. } 279+ \\
23 \mathrm{C}>\mathrm{T}\end{array}$ & Italy & $\mathrm{F}$ & 43 & $\begin{array}{l}\text { Secondary amenor- } \\
\text { rhoea, headache } \\
\text { and transient visual } \\
\text { defects }\end{array}$ & $\begin{array}{l}\text { Ma-SSE } \\
\quad(18 \mathrm{~mm}), \\
\text { Inv }-\end{array}$ & $\begin{array}{l}\text { PRL 30, } \\
\text { GH 0.2, } \\
\text { IGF-I 152 }\end{array}$ & None & $\begin{array}{l}\text { See values at } \\
\text { diagnosis }\end{array}$ & $\begin{array}{r}\text { PRL, GH }( \pm) \\
\text { Ki-67, 3.0\% }\end{array}$ & $+1-$ & $\mathrm{C}-\mathrm{N}-$ \\
\hline $\begin{array}{l}\text { Spor } 8^{(\mathrm{T})} \\
\text { TS }\end{array}$ & $\mathrm{R} 304 \mathrm{X}$ & Italy & $\mathrm{F}$ & 17 & $\begin{array}{l}\text { Visual defects, } \\
\text { headache, sec- } \\
\text { ondary amenor- } \\
\text { rhoea and DH } \\
171 \mathrm{~cm}\end{array}$ & $\begin{array}{l}\text { Ma-SSE, } \\
\text { Inv - }\end{array}$ & $\begin{array}{l}\text { GH 9.0, } \\
\text { IGF-I 905, } \\
\text { PRL } 57\end{array}$ & None & $\begin{array}{l}\text { See values at } \\
\text { diagnosis }\end{array}$ & $\begin{array}{l}\mathrm{GH}, \mathrm{Ki}-67 \\
3.0 \%\end{array}$ & $+1-$ & ND \\
\hline
\end{tabular}

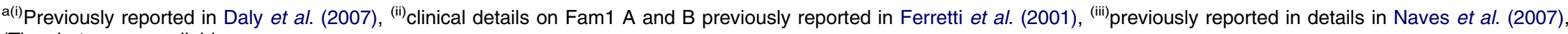
(T) only tumour available.

${ }^{\mathrm{b}} \mathrm{DH}$, definitive height.

Ma, macroadenoma; SSE, suprasellar extension; maximal tumour diameter within brackets; Inv-, non-invasive; Inv + , invasive; CS, cavernous sinus.

${ }^{\mathrm{d}}$ AIP staining with semi-quantitative score. ++ strong, diffuse; + moderate, diffuse; $+/-$ weak or scattered positive cells; - negative

${ }^{\mathrm{e}} \mathrm{AHR}$ staining; C, cytoplasmic staining with an N-terminal monoclonal antibody; N, nuclear staining with a C-terminal polyclonal antibody respectively; ND, not done (unavailable material). 
Table 3 Characteristics of somatotrophinomas and relationship with the presence of aryl hydrocarbon receptor-interacting protein $(A I P)$ mutations

\begin{tabular}{|c|c|c|c|}
\hline & Group A & Group B & $\boldsymbol{P}$ \\
\hline \multicolumn{4}{|l|}{ Patients } \\
\hline Age & $18.7 \pm 6.6$ & $40.1 \pm 12.5$ & $P<0.0001$ \\
\hline Sex & $7 \mathrm{M} / 5 \mathrm{~F}$ & $13 \mathrm{M} / 17 \mathrm{~F}$ & NS \\
\hline \multicolumn{4}{|l|}{ Tumours } \\
\hline Suprasellar extension & $10 / 14(71.4 \%)$ & $16 / 32(50.0 \%)$ & NS \\
\hline Invasive & $10 / 14(71.4 \%)$ & $12 / 32(37.5 \%)$ & $\chi^{2}=4.49, P=0.034$ \\
\hline $\mathrm{Ki}-67,>3.0 \%$ & $5 / 11(45.4 \%)$ & $6 / 29(20.7 \%)$ & NS \\
\hline Pre-operative treatment & $7 / 14(50.0 \%)$ & $13 / 32(40.6 \%)$ & NS \\
\hline \multicolumn{4}{|l|}{ AIP expression } \\
\hline$A I P / \beta$-actin mRNA (n) & $0.18 \pm 0.05(4)$ & $1.05 \pm 0.98(16)$ & $P=0.072$ \\
\hline AIP score $(-;+/-;+;++)$ & $2 ; 8 ; 3 ; 1$ & $1 ; 10 ; 15 ; 4$ & NS \\
\hline Low AIP score $(+/-,-)$ & $10 / 14(71.4 \%)$ & $11 / 30(36.7 \%)$ & $\chi^{2}=4.62, P=0.031$ \\
\hline \multicolumn{4}{|l|}{ AHR expression } \\
\hline$A H R / \beta$-actin mRNA (n) & $0.01 \pm 0.02(4)$ & $0.02 \pm 0.03(16)$ & NS \\
\hline AHR score $(\mathrm{N}-\mathrm{mAb})(-; \pm ;+)$ & $10 ; 2 ; 0$ & $15 ; 12 ; 2$ & NS \\
\hline Detectable AHR $(\mathrm{N}-\mathrm{mAb})(+I-,+)$ & $2 / 12(16.7 \%)$ & $14 / 29(48.3 \%)$ & $\chi^{2}=3.56, P=0.059$ \\
\hline Nuclear AHR (C-pAb) & $0 / 7$ & $2 / 13$ & NS \\
\hline
\end{tabular}

Groups $\mathrm{A}$ and $\mathrm{B}$ refer to patients and tumours with or without documented $A I P$ mutations respectively. AIP/ $\beta$-actin and $A H R / \beta$-actin mRNA ratios were obtained by real-time RT-PCR (the number of studied tumours is indicated in italicized text within brackets). Semi-quantitative AIP and AHR scores were defined by immunohistochemistry ( + + diffuse, strong; + diffuse, moderate; +/ weak immunostaining and/or scattered positive cells; - negative), using anti-AIP and AHR (N-mAb) monoclonal antibodies and, in a subset of cases, a polyclonal anti-AHR antibody (C-pAb) recognizing the C-terminal half of AHR respectively. Nearly significant $P$ values are indicated in italics; NS, non-significant.

detectable (scores $+/-$ and + ) versus undetectable AHR immunostaining respectively. The level of significance was set at $P<0.05$.

\section{Results}

\section{Normal pituitary}

$A I P$ and $A H R$ transcripts were detected in normal pituitary samples, with a significantly lower expression of $A H R(P<0.0001$ versus AIP $)$. Accordingly, AIPimmunopositive cells were largely present in the adenohypophysis (see Supplementary Fig. 1A, which can be viewed online at http://erc.endocrinologyjournals.org/supplemental/), with topographical studies arguing for a preferential strong and diffuse expression in somatotrophs (see Supplementary Fig. 1B), and to a lesser extent by lactotrophs (data not shown). AHR (N-mAb) immunostaining was less intense, with a roughly similar, although more scattered and diffuse, cell distribution (see Supplementary Fig. 1C). AIP and AHR (N-mAb) immunostaining was confined to the cytoplasm (see Supplementary Fig. 1D and E), although some degree of AHR nuclear positivity was revealed by $\mathrm{C}-\mathrm{pAb}$ immunostaining (see Supplementary Fig. 1F). Some scattered AIP- and AHR-immunopositive cells were observed in the pars intermedia, containing
ACTH-secreting cells (see Supplementary Fig. 1G-I). Double immunostaining with AHR C-pAb revealed co-localization of AHR with AIP (see Supplementary Fig. 1J), nuclear AHR immunostaining being observed in a subset of somatotrophs (see Supplementary Fig. 1K) and a few corticotrophs (data not shown), whereas in lactotrophs, AHR appeared to be mostly perinuclear (see Supplementary Fig. 1L). FSH-secreting cells were virtually negative for nuclear AHR (data not shown).

\section{Pituitary adenomas}

The expression of AIP and AHR has been first performed on the entire series of PA. AIP and AHR transcripts were detected in all PA (Fig. 1), with a markedly lower AHR expression $(P<0.0001$ versus $A I P)$. Accordingly, AIP and AHR proteins were detected in 84.0 and $38.6 \%$ of the cases respectively. Marked individual variations were observed in AIP gene expression and immunostaining (Fig. 1A; Table 1) - examples of IHC scoring are shown in Fig. 2A-C, including one microprolactinoma with a normal pituitary fragment shown as an internal control (Fig. 2D). The AIP immunostaining score was significantly correlated with AIP expression $(P=0.0014)$ and with the AHR $(\mathrm{N}-\mathrm{mAb})$ score $\left(\chi^{2}=18.1, P=0.006\right)$. However, cytoplasmic AHR 

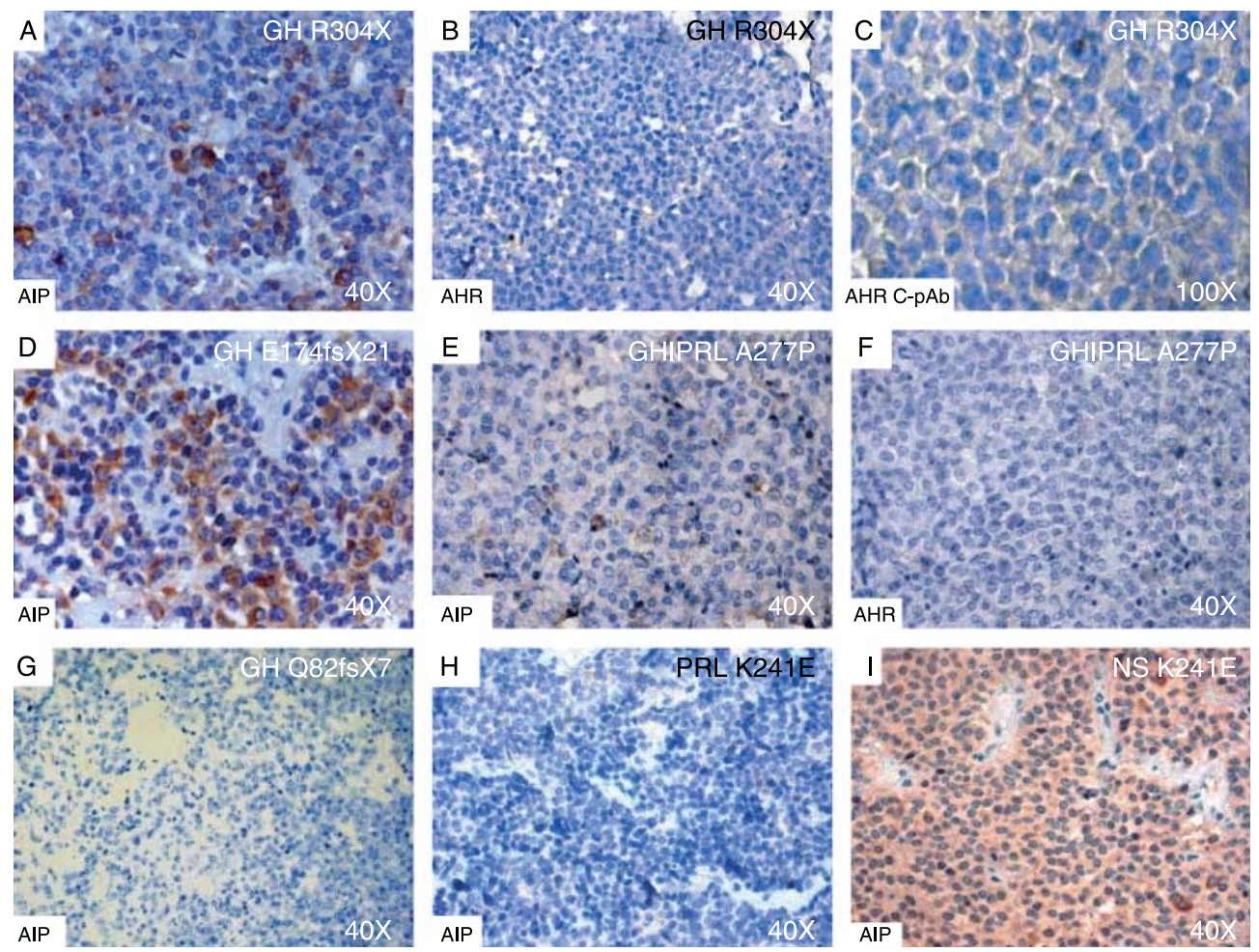

Figure 3 AIP and AHR immunostaining in AIP ${ }^{\text {mut }}$ pituitary adenomas. Examples of AIP and AHR immunostaining and relative semiquantitative AIP evaluation in AIP ${ }^{\text {mut }}$ PA with references to Table 2 for case identification. (A) AIP immunostaining in a familial somatotrophinoma (Fam 1A) with a R304X mutation (+/-, an area displaying scattered positive cells), with no detectable AHR in the cytoplasm (B) or in the nucleus (C). (D) AIP immunostaining (+) in a familial somatotrophinoma (Fam 4) with an E174fsX21 mutation. (E) Low AIP immunostaining $(+/-)$ and $(F)$ lack of detectable AHR immunostaining in a sporadic somatotrophinoma with a germline A277P mutation (Spor2). (G) Negative AIP immunostaining in a sporadic somatotrophinoma with a Q82fsX7 mutation. Differential expression of AIP in two siblings (Fam 3) with a K241E mutation, affected by a prolactinoma (H) (quoted -) and a NS adenoma (I) (quoted + ) respectively.

immunostaining $(\mathrm{N}-\mathrm{mAb})$ was generally weak, and nuclear immunostaining $(\mathrm{C}-\mathrm{pAb})$ was observed in a minority of cases $(12 / 61=19.7 \%$; Fig. 2E-I), including a familial NS PA with normal AIP sequencing (Fig. 2I).

\section{Correlation with clinical characteristics}

A series of factors were found to account for the variations in AIP mRNA and AIP immunostaining observed on the entire series of PA, including tumour phenotype and aggressiveness (Table 1). Briefly, both were found to be highly variable in somatotrophinomas, generally low in prolactinomas and in other secreting PA, but paradoxically high in a subset of NS adenomas (Fig. 1A; Table 1). AIP mRNA was significantly lower in invasive PA $(P=0.0197$ versus non-invasive), which were also more likely to show a low AIP immunostaining $\left(\chi^{2}=6.91, P=0.009\right.$ versus non-invasive). Overall, no significant difference in AIP expression was observed according to the AIP gene status (data not shown). AHR mRNA was poorly influenced by phenotype (Fig. 1B), but complete loss of AHR immunostaining ( $\mathrm{N}-\mathrm{mAb})$ was significantly more frequent in invasive ( 71.4 vs $47.4 \%$ in noninvasive, $\left.\chi^{2}=5.2, P=0.022\right)$ and in $A I P^{\mathrm{mut}} \mathrm{PA}(86.7$ vs $58.7 \%$ in non-mutated PA, $\chi^{2}=3.92, P=0.048$ ). Nuclear AHR immunostaining (C-pAb) was observed in three somatotrophinomas, three prolactinomas and six NS adenomas respectively, but in none of the $A I P^{\mathrm{mut}} \mathrm{PA}$ included in this study.

\section{Analysis of PA subgroups}

Because the proportion of $A I P^{\text {mut }}$ tumours varied according to phenotype, data obtained in all somatotrophinomas, prolactinomas and NS adenomas have been further analysed as distinct subgroups.

\section{Somatotrophinomas}

As most $A I P^{\text {mut }}$ tumours were somatotrophinomas, data were analysed according to the presence (group A) or the absence (group B) of documented AIP mutations 
respectively. In group A, AIP mutations were identified on patient's leukocyte DNA in six FIPA patients (eight PA) and in five sporadic cases, respectively, and on tumour cDNA and DNA in an additional sporadic case where no leukocyte DNA was available. Individual data are shown in Table 2 (Family 1, 2 and 4; Spor 2-6 and 8 ). Germline mutations were heterozygous whereas only the mutated allele was detected in cDNA/tDNA where available, thereby indicating somatic loss of heterozygosity in four out of five cases (Fam 1B and C, Fam 2B; Spor 2) and strongly suggesting hemizygosity in the other case (Spor 8). In group $\mathrm{B}$, the lack of detectable AIP mutations was confirmed in most cases by sequencing of gDNA $(n=7)$, tumour cDNA $(n=12)$ and/or tDNA $(n=4)$ respectively. Data observed in group A and group B are summarized in Table 3. Somatotrophinomas occurred in group $\mathrm{A}$ at a significantly younger age $(P<0.0001)$ were more frequently invasive $(P=0.034)$ and more likely to display decreased AIP immunostaining $(P=0.031)$ than those in group B respectively. Of note, the pattern of AIP immunostaining could differ according to the mutation (Fig. 3A, D, E and G). Similarly, there was a trend towards cytoplasmic AHR $(\mathrm{N}-\mathrm{mAb})$ being less likely to be detected in group A (Fig. 3B and $\mathrm{F})$ than in group $\mathrm{B}(P=0.059)$. Further evaluation with the AHR C-pAb confirmed the lack of nuclear immunostaining in group A (Fig. 3C).

Excluding somatotrophinomas with undetermined AIP gene status, AIP mutations were estimated to account for AIP gene down-regulation in 3 out of 4 cases and for low AIP immunostaining in 10 out of 19 cases respectively. Low AIP immunostaining tended to be more frequent in $A I P^{\text {mut }}$ somatotrophinomas than in those with normal $A I P$ sequencing ( 10 out of 14 vs 9 out of $22, \chi^{2}=3.20, P=0.074$ ), indicating a sensitivity of IHC in detecting AIP mutations of $71.4 \%$ and a specificity of $40.9 \%$ respectively. According to logistic regression analysis, tumour invasiveness was the only independent predictor of AIP down-regulation in somatotrophinomas $(P=0.019)$, whereas young age was the only independent predictor of $A I P$ mutations $(P=0.002$; see Supplementary Table 2 , which can be viewed online at http://erc.endocrinology-journals.org/supplemental/). Complete loss of AHR (N-mAb) immunostaining was significantly more frequent in invasive than in noninvasive somatotrophinomas ( 78.9 vs $35.7 \%, \chi^{2}=4.7$, $P=0.012$ ), while a trend was confirmed in $A I P^{\text {mut }}$ somatotrophinomas as compared with those with normal AIP sequencing (83.3 vs 52.4.\%, $\chi^{2}=2.76$, $P=0.096)$.

\section{Prolactinomas}

Both AIP mRNA and AIP immunostaining were generally low in prolactinomas (Table 1; Figs 1 and $2 \mathrm{C}$ and $\mathrm{E})$. The AIP gene status was available in most cases (15 out of 22), according to AIP sequencing performed on gDNA $(n=8)$ or tumour cDNA $(n=7)$. Germline AIP mutations were identified in three cases (Table 2, Fam 3B; Spor 1 and 7), although no splicing alteration was found by tumour cDNA sequencing in Spor 7. Low AIP immunostaining occurred in prolactinomas with normal AIP sequencing (10 out of 12) as well as in $A I P^{\text {mut }}$ ( 2 out of 3 ). Excluding $A I P^{\text {mut }}$ tumours, low AIP immunostaining was confirmed to be significantly more frequent in prolactinomas than in somatotrophinomas $\left(\chi^{2}=16.5, P=0.0009\right)$. Cytoplasmic (N-mAb) and nuclear (C-pAb) AHR immunostaining could be detected in 11 out of $21(52.3 \%)$ and 3 out of $17(17.6 \%)$ prolactinomas respectively.

\section{NS adenomas}

The mean AIP mRNA in NS adenomas was similar to that observed in somatotrophinomas, $42.3 \%$ of PA in this group also displaying significant AIP immunostaining (Table 1; Figs 1 and 2B). A germline AIP mutation was identified in one FIPA patient (Table 2, Fam 3A), and normal AIP sequencing was documented in 11 cases on tumour cDNA $(n=8)$ or tDNA $(n=3)-$ including all NS occurring in patients aged $\leq 50$ years old. Surprisingly, a significant AIP immunostaining was observed in the $A I P^{\mathrm{mut}} \mathrm{NS}$ adenoma (Fig. 3I), but not in the prolactinoma that was surgically resected in her brother (Fig. 3H). AIP immunostaining was frequently associated with nuclear AHR (55.5 vs 9.0\% according to the presence or the absence of significant AIP respectively, $\chi^{2}=5.09, P=0.02$ ), which in turn was significantly correlated with cytoplasmic AHR $\left(\chi^{2}=11.6, P=0.0007\right)$. No significant correlation was found between AIP and AHR immunostaining and tumour volume, invasiveness or immunostaining for gonadotrophins.

\section{Discussion}

This study shows for the first time that both AHR and AIP are expressed in the normal human pituitary and frequently down-regulated in PA. In normal pituitaries, topographical studies indicated a preferential expression of AIP by somatotrophs, which display a strong and diffuse expression, and to a lesser extent by lactotrophs. These findings are in agreement with recent work by Leontiou et al. (2008), which also localized AIP within GH and PRL-containing 
secretory granules in normal cells. Scattered AIPexpressing cells were also observed in the pars intermedia. AHR was expressed at lower transcriptional levels and with a lower immunostaining intensity than AIP, with scattered AHR-expressing cells being more widely distributed than AIPexpressing cells. AIP and AHR were first observed in the cytoplasm only. However, further evaluation with an antibody directed against the C-terminal part of the AHR protein revealed moderate nuclear immunostaining in a subset of somatotrophs and in some corticotrophs. Differences between cytoplasmic and nuclear staining may reflect variations in proteinprotein interactions involving AHR in subcellular compartments, which may in turn influence epitope recognition and modify the sensitivity of the corresponding IHC assays. As DNA binding and basic-helix-loop-helix (bHLH) -interacting domains of AHR are located N-terminal (Fukunaga et al. 1995, Fukunaga \& Hankinson 1996), the N-mAb epitope of AHR may be masqueraded in its transcriptionally active conformation. Thus, nuclear immunostaining with the C-terminal antibody alone may indicate some degree of endogenous AHR activity. Supporting a role for AHR in pituitary development and/or cell differentiation, binding sites for the pituitary transcription factors Lhx3 and Pit-1 are present in the promoter of the AHR gene (Harper et al. 2006). Constitutive expression of AHR and ARNT has been shown in the rat hypothalamus (Korkalainen et al. 2005). These data suggest a physiological role for AHR in the human hypothalamus-pituitary unit, further extending the spectrum of bHLH transcription factors expressed in the normal pituitary and PA (Jackson et al. 1993, Ferretti et al. 2001, Huang et al. 2002, Fratticci et al. 2007).

In agreement with a recent report (Leontiou et al. 2008), AIP was found by real-time RT-PCR to be expressed at a transcriptional level in all PA, with a relative overexpression in a subset of somatotrophinomas and NS adenomas. Accordingly, significant AIP immunostaining was observed in about half of somatotrophinomas and NS adenomas, but in $\leq 15 \%$ of other PA. Thus, AIP expression can be either retained or down-regulated in somatotrophinomas and is frequently decreased in prolactinomas, whereas abnormal AIP expression may occur in a subset of NS adenomas.

We first focused our attention on the significance of AIP down-regulation in somatotrophinomas. In these tumours, decreased gene and protein expression of AIP were significantly associated with the presence of aggressive features and, although AIP immunostaining tended to be lower in $A I P^{\text {mut }}$ somatotrophinomas, only invasiveness was an independent predictor of AIP loss. On the other hand, young age $(<30$ years of age) was an independent predictor for the presence of AIP mutations, but not for low AIP immunostaining. These findings may have interesting pathogenetic and clinical implications. First, they strongly suggest that AIP down-regulation may be involved in the progression of somatotrophinomas, regardless of detectable germline AIP mutations. Although we cannot exclude the presence of large AIP genomic deletions, this is unfrequent (Georgitsi et al. 2008b), and additional mechanisms of AIP silencing may be present. Second, such data contrast with those obtained in prolactinomas, where a low AIP expression could be observed at early stages of the disease, suggesting a peculiar role for AIP in somatotrophs. This could explain the large predominance of somatotrophinomas among PA developing in patients with germline AIP mutations, as reported in this and other studies (Cazabat et al. 2007, Daly et al. 2007), and the frequent aggressiveness of $A I P^{\text {mut }}$ somatotrophinomas (Daly et al. 2007, Iwata et al. 2007, Toledo et al. 2007, this study). This is consistent with the high expression of AIP in normal somatototrophs, and supported by functional experiments on $\mathrm{GH}_{3}$ cells (Leontiou et al. 2008). Third, IHC may not be as suitable as previously suggested for the pre-screening of patients with germline AIP mutations (Georgitsi et al. 2007). Indeed, our data support recent evidence that AIP can frequently be detected in $A I P^{\text {mut }}$ tumours (Leontiou et al. 2008). Such discrepancies may depend on the type of mutation and, to a lesser extent, antibody characteristics. Due to somatic hemizygosity for the mutated AIP allele, as further supported by cDNA sequencing in this study, IHC data will depend on epitope expression by the mutated protein, if actually transcribed. In fact, AIP immunostaining can theoretically be retained unless early stop mutations are present. Early data on IHC were obtained in series where Finnish patients and their distinctive Q14X early stop mutation were largely represented (Georgitsi et al. 2007). Although the AIP immunoscore in $A I P^{\text {mut }}$ somatotrophinomas can also be low due to mono-allelic gene expression, this is of limited diagnostic interest, since semi-quantitative interpretation of IHC is difficult to standardize and can be confounded readily. Thus, evidence of AIP immunostaining should not discourage AIP gene sequencing in acromegalics with a familial history of FIPA or a young age at disease onset. Furthermore, IHC is unsuitable as a pre-screening tool in prolactinomas, due to the frequent loss of significant AIP immunostaining in this group. 
The familial AIP mutations reported herein (E174fs, K241E, Q285fs and R304X) were previously published (Daly et al. 2007, Naves et al. 2007), whereas seven out of the eight nucleotide changes identified in patients with sporadic PA were undescribed. They consisted of one frameshift (Q82fs) and three missense (R128H, V195A and A277P) mutations respectively, three intronic changes (IVS2 c.279+23C $>$ T, IVS3 c. $468+16 \mathrm{G}>\mathrm{T}$ and IVS3 c. $468+15 \mathrm{C}>\mathrm{T}$ ) being also recognized. None was observed in controls and comparison with available SNPs, and orthologue sequences' databases were performed (see the electronic Supplementary Materials and methods). Briefly, the Q82fs frameshift mutation is expected to encode for a truncated protein after seven amino acids. None of the novel missense changes has been identified as a SNP to date, the amino acid residues K(241), V(195) and $\mathrm{A}(277)$ are highly conserved among species, and loss of the wild-type allele could be verified by cDNA sequencing in the latter case. In contrast, the presence of an arginine or a histidine at position 128 variant occurs variably across mammalian species and may represent an unrecognized human polymorphism, which might explain normal AIP immunostaining in this case. However, the exclusion of this case from $A I P^{\text {mut }}$ somatotrophinomas did not significantly alter the statistical results obtained in this group (data not shown). Of note, in the siblings affected by a K241E mutation, AIP immunostaining was present in the NS PA, but absent in the prolactinoma. This may reflect the differential AIP expression in these two phenotypes, regardless of the AIP mutation itself, which should not affect the epitope recognized by the mAb used in this study. The novel intronic changes, none of them being encountered in controls, are not expected to induce alterations in AIP splicing by in silico analysis, and this was confirmed by cDNA sequencing in the prolactinoma associated with a germline change in intron 2. However, the contiguity of the two nucleotide changes in intron 3 and the young age of the affected patients, both with somatotrophinomas with a low or heterogeneous AIP immunostaining, favour their possible role in the onset of the disease and suggest possible molecular implications of intronic changes outside recognized splicing sites (Kleinjan \& van Heiningen 2005). The R304X mutation was identified in an additional sporadic somatotrophinoma - a young Italian patient unrelated to the family included in this study, which was previously reported in detail (Ferretti et al. 2001, Daly et al. 2007). This mutation has been recurrently recognized in Europe (Vierimaa et al. 2006, Cazabat et al. 2007, Daly et al. 2007, Leontiou et al. 2008), and R304Q mutations being occasionally reported also (Georgitsi et al. 2007, Leontiou et al. 2008). This reinforces the concept of codon 304 as a relative 'hot spot' in the AIP gene, although some founder effect concerning the R304X mutation cannot be excluded. Of note, AIP was detected by IHC in all R304X somatotrophinomas studied so far and, where available, electron microscopy showed sparsely granulated somatotrophinomas (Ferretti et al. 2001, Leontiou et al. 2008).

Another major aim of this study was to investigate for the first time the possible role of AHR in the pathogenesis of PA, especially in $A I P^{\text {mut }}$ tumours. Low levels of $A H R$ transcripts were found in PA as well as in normal pituitary samples. Cytoplasmic AHR immunostaining was detected in $40.0 \%$ of PA, being generally weaker in intensity as compared with normal pituitaries, and significantly correlated with AIP immunostaining. This is consistent with AHR destabilization in the presence of low AIP levels, thereby supporting a role for AIP in AHR cytoplasmic stabilization in the human pituitary, as observed in most tissues. In $A I P^{\text {mut }} \mathrm{PA}, \mathrm{AHR}$ can be further destabilized by a defective interaction with the AIP protein. As the C-terminal half of AIP is critical for interaction with AHR, which is abolished by truncation of the last five amino acids (Bell \& Poland 2000), AIPtruncating mutations are expected to prevent the constitution of the cytoplasmic complex. The functional implications of each missense mutation would need specific in vitro experiments, but a number of single amino acid changes occurring in the TPR region can abolish AIP binding to hsp90 and/or strongly reduce AIP/AHR interaction (Bell \& Poland 2000, Petrulis \& Perdew 2002). The N-terminal part of AIP may also contribute to the cytoplasmic stabilization of AHR (Kazlauskas et al. 2002). Accordingly, none of the $A I P^{\text {mut }}$ PA showed nuclear AHR staining, suggesting that increased AHR nuclear signalling is not implicated in AIP-related tumourigenesis. Hence, AHR down-regulation may be involved in $A I P^{\text {mut }}$ and/or invasive somatotrophinomas, although we cannot exclude a non-specific bystander effect of AIP down-regulation. In contrast, AHR appears to be up-regulated in a subset of NS overexpressing AIP. Of note, NS but not GH-secreting PA have been reported after Seveso's exposure (Pesatori et al. 2008). These findings suggest a differential role of AHR in pituitary cells, and further in vitro investigations should help clarifying these issues.

In addition to AHR modulation, AIP is known to interact with a number of cytoplasmic proteins including phosphodiesterases (Bolger et al. 2003, de Oliveira et al. 2007), thereby possibly modulating 
cAMP concentration, survivin, an anti-apoptotic protein (Kang \& Altieri 2006), and Ret (Vargiolu et al. 2009). Interactions with phosphodiesterases can be altered by AIP mutations (Bolger et al. 2003, de Oliveira et al. 2007). Possible alterations in cAMP signalling or apoptosis accompanying down-regulation of AIP in somatotrophinomas or increased AIP expression in NS PA should be further investigated.

In conclusion, this study supports the role of AIP in the cytoplasmic stabilization of AHR and shows that reduced AIP and AHR expression are frequently observed in PA, at least at a protein level, with the exception of NS adenomas, in which up-regulation of both proteins can be observed. It suggests a possible role for AIP and AHR down-regulation in the progression of somatotrophinomas, independently from germline mutations, and indicates that IHC is not a sufficiently sensitive tool for the detection of AIP mutations in somatotrophinomas, and is unsuitable to this purpose in prolactinomas or NS PA.

\section{Declaration of interest}

The authors declare that there is no conflict of interest that could be perceived as prejudicing the impartiality of the research reported.

\section{Funding}

This work was partially supported by grants from the Italian Ministry for University and Research (MIUR), Neuromed Institute, IRCCS, and the 'Carlo Ferri' Foundation for the prevention in oncology, Italy, and by the Fonds d'Investissement pour la Recherche Scientifique 2007 (FIRS) du CHU de Liège, Belgium.

\section{Acknowledgements}

The authors wish to thank Maria-Antonietta Oliva and Dr Remo Bernabei for their excellent technical assistance, Pr Luiz Augusto Casulari and Dr Maria Yaneva for their contribution to patients' follow-up.

\section{References}

Barlier A, Vanbellinghen JF, Daly AF, Silvy M, Jaffrain-Rea ML, Trouillas J, Tamagno G, Cazabat L, Bours V, Brue T et al. 2007 Mutations in the aryl hydrocarbon receptor interacting protein gene are not highly prevalent among subjects with sporadic pituitary adenomas. Journal of Clinical Endocrinology and Metabolism 92 1952-1955.

Barouki R, Coumoul X \& Fernandez-Salguero P 2007 The aryl hydrocarbon receptor, more than a xenobioticinteracting protein. FEBS Letters $\mathbf{5 8 1}$ 3608-3615.
Beckers A \& Daly AF 2007 The clinical, pathological, and genetic features of familial isolated pituitary adenomas. European Journal of Endocrinology 157 371-382.

Bell DR \& Poland A 2000 Binding of aryl hydrocarbon receptor (AhR) to AhR-interacting protein. Journal of Biological Chemistry 275 36407-36414.

Bolger GB, Peden AH, Steele MR, MacKenzie C, McEwan DG, Wallace DA, Huston E, Baillie GS \& Houslay MD 2003 Attenuation of the activity of the cAMP-specific phosphodiesterase PDE4A5 by interaction with the immunophilin XAP2. Journal of Biological Chemistry 278 33351-33363.

Buchbinder S, Bierhaus A, Zorn M, Nawroth PP, Humpert P \& Schilling T 2008 Aryl hydrocarbon receptor interacting protein gene (AIP) mutations are rare in patients with hormone secreting or non-secreting pituitary adenomas. Experimental and Clinical Endocrinology \& Diabetes 116 625-628.

Cazabat L, Libè R, Perlemoine K, René-Corail F, Burnichon N, Gimenez-Roqueplo AP, Dupasquier-Fediaevsky L, Bertagna X, Clauser E, Chanson P et al. 2007 Germline inactivating mutations of the aryl hydrocarbon receptorinteracting protein gene in a large cohort of sporadic acromegaly: mutations are found in a subset of young patients with macroadenomas. European Journal of Endocrinology 157 1-8.

Daly AF, Jaffrain-Rea ML, Ciccarelli A, Valdes-Socin H, Rohmer V, Tamburrano G, Borson-Chazot C, Estour B, Ciccarelli E, Brue T et al. 2006 Clinical characterization of familial isolated pituitary adenomas. Journal of Clinical Endocrinology and Metabolism 91 3316-3323.

Daly AF, Vanbellinghen JF, Khoo SK, Jaffrain-Rea ML, Naves LA, Guitelman MA, Murat A, Emy P, GimenezRoqueplo AP, Tamburrano G et al. 2007 Aryl hydrocarbon receptor-interacting protein gene mutations in familial isolated pituitary adenomas: analysis in 73 families. Journal of Clinical Endocrinology and Metabolism 92 1891-1896.

Elango A, Shepherd B \& Chen TT 2006 Effects of endocrine disruptors on the expression of growth hormone and prolactin mRNA in the rainbow trout pituitary. General and Comparative Endocrinology 145 116-127.

Ferretti E, Jaffrain-Rea ML, Asteria C, Di Stefano D, Esposito V, Ferrante L, Daniele P, Tiberti C, Gallucci M, Bosman C et al. 2001 Two familial giant pituitary adenomas associated with overweight: clinical, morphological and genetic features. European Journal of Endocrinology 144 227-235.

Fratticci A, Grieco FA, Spilioti C, Giangaspero F, Ventura L, Esposito V, Piccirilli M, Santoro A, Gulino A, Cantore G et al. 2007 Differential expression of neurogenins and NeuroD1 in human pituitary tumours. Journal of Endocrinology 194 475-484.

Fukunaga BN \& Hankinson O 1996 Identification of a novel domain in the aryl hydrocarbon receptor required for DNA binding. Journal of Biological Chemistry 271 3743-3749. 
Fukunaga BN, Probst MR, Reisz-Porszasz S \& Hankinson O 1995 Identification of functional domains of the aryl hydrocarbon receptor. Journal of Biological Chemistry $27029270-29278$.

Gasiewicz TA, Henry EC \& Collins LL 2008 Expression and activity of aryl hydrocarbon receptors in development and cancer. Critical Reviews in Eukaryotic Gene Expression 18 279-321.

Georgitsi M, Raitila A, Karhu A, Tuppurainen K, Mäkinen MJ, Vierimaa O, Paschke R, Saeger W, van der Luijt RB, Sane T et al. 2007 Molecular diagnosis of pituitary adenoma predisposition caused by aryl hydrocarbon receptor-interacting protein gene mutations. PNAS 104 4101-4105.

Georgitsi M, De Menis E, Cannavò S, Mäkinen MJ, Tuppurainen K, Pauletto P, Curtò L, Weil RJ, Paschke R, Zielinski G et al. 2008a Aryl hydrocarbon receptor interacting protein (AIP) gene mutation analysis in children and adolescents with sporadic pituitary adenomas. Clinical Endocrinology 69 621-627.

Georgitsi M, Heliövaara E, Paschke R, Kumar AV, Tischkowitz M, Vierimaa O, Salmela P, Sane T, De Menis E, Cannavò S et al. 2008b Large genomic deletions of aryl hydrocarbon receptor interacting protein (AIP) gene in pituitary adenoma predisposition. Journal of Clinical Endocrinology and Metabolism 93 4146-4151.

Harper PA, Riddick DS \& Okey AB 2006 Regulating the key regulator: factors that control levels and activity of the aryl hydrocarbon receptor. Biochemical Pharmacology $\mathbf{7 2}$ 267-279.

Huang P, Ceccatelli S, Håkansson H, Grandison L \& Rannug A 2002 Constitutive and TCDD-induced expression of Ah receptor-responsive genes in the pituitary. Neurotoxicology 23 783-793.

Iwata T, Yamada S, Mizusawa N, Golam HM, Sano T \& Yoshimoto K 2007 The aryl hydrocarbon receptorinteracting protein gene is rarely mutated in sporadic GH-secreting adenomas. Clinical Endocrinology 66 499-502.

Jackson SM, Barnhart KM, Mellon PL, Gutierrez-Hartmann A \& Hoffler JP 1993 Helix-loop-helix proteins are present and differentially expressed in different cell lines from the anterior pituitary. Molecular and Cellular Endocrinology 96 167-176.

Jaffrain-Rea ML, Di Stefano D, Minniti G, Esposito V, Bultrini A, Ferretti E, Santoro A, Faticanti Scucchi L, Gulino A \& Cantore G 2002 A critical reappraisal of MIB-1 labelling index significance in a large series of pituitary tumours: secreting versus non-secreting adenomas. Endocrine-Related Cancer 9 103-113.

Kang BH \& Altieri DC 2006 Regulation of survivin stability by the aryl hydrocarbon receptor-interacting protein. Journal of Biological Chemistry $\mathbf{2 8 1}$ 24721-24727.
Kazlauskas A, Poellinger L \& Pongratz I 2002 Two distinct regions of the immunophilin-like protein XAP2 regulate dioxin receptor function and interaction with hsp90. Journal of Biological Chemistry 277 11795-11801.

Kleinjan DA \& van Heiningen V 2005 Long-range control of gene expression: emerging mechanisms and disruption in disease. American Journal of Human Genetics 76 8-32.

Korkalainen M, Lindén J, Tuomisto J \& Pohjanvirta R 2005 Effect of TCDD on mRNA expression of genes encoding bHLH/PAS proteins in rat hypothalamus. Toxicology 208 1-11.

LaPres JJ, Glover E, Dunham EE, Bunger MK \& Bradfield CA 2000 ARA9 modifies agonist signaling through an increase in cytosolic aryl hydrocarbon receptor. Journal of Biological Chemistry 275 6153-6159.

Leontiou CA, Gueorguiev M, van der Spuy J, Quinton R, Lolli F, Hassan S, Chahal HS, Igreja SC, Jordan S, Rowe J et al. 2008 The role of the aryl hydrocarbon receptorinteracting protein gene in familial and sporadic pituitary adenomas. Journal of Clinical Endocrinology and Metabolism 93 2390-2401.

Marlowe JL \& Puga A 2005 Aryl hydrocarbon receptor, cell cycle regulation, toxicity, and tumorigenesis. Journal of Cellular Biochemistry 96 1174-1184.

Naves LA, Daly AF, Vanbellinghen JF, Casulari LA, Spilioti C, Magalhães AV, Azevedo MF, Giacomini LA, Nascimento PP, Nunes RO et al. 2007 Variable pathological and clinical features of a large Brazilian family harbouring a mutation in the aryl hydrocarbon receptor-interacting protein gene. European Journal of Endocrinology 157 383-391.

Nguyen LP \& Bradfield CA 2008 The search for endogenous activators of the aryl hydrocarbon receptor. Chemical Research in Toxicology 21 102-116.

Nishimura N, Miyabara Y, Sato M, Yonemoto J \& Tohyama C 2002 Immunohistochemical localization of thyroid stimulating hormone induced by a low oral dose of 2,3,7,8-tetrachlorodibenzo- $p$-dioxin in female SpragueDawley rats. Toxicology 171 73-82.

de Oliveira SK, Hoffmeister M, Gambaryan S, Müller-Esterl W, Guimaraes JA \& Smolenski AP 2007 Phosphodiesterase 2A forms a complex with the co-chaperone XAP2 and regulates nuclear translocation of the aryl hydrocarbon receptor. Journal of Biological Chemistry 282 13656-13663.

Pesatori A, Baccarelli A, Consonni D, Lania A, Beck-Peccoz P, Bertazzi P \& Spada A 2008 Aryl hydrocarbon receptor interacting protein and pituitary adenomas: a populationbased study on subjects exposed to dioxin after the Seveso, Italy, accident. European Journal of Endocrinology 159 699-703.

Petrulis JR \& Perdew GH 2002 The role of chaperone proteins in the aryl hydrocarbon receptor core complex. Chemico-Biological Interactions 141 25-40. 
Pitt JA, Buckalew AR, House DE \& Abbott BD 2000 Adrenocorticotropin (ACTH) and corticosterone secretion by perifused pituitary and adrenal glands from rodents exposed to 2,3,7,8-tetrachlorodibenzo- $p$-dioxin (TCDD). Toxicology 151 25-35.

Pocar P, Fischer B, Klonisch T \& Hombach-Klonisch S 2005 Molecular interactions of the aryl hydrocarbon receptor and its biological and toxicological relevance for reproduction. Reproduction 129 379-389.

Popp JA, Crouch E \& McConnell EE 2006 A weightof-evidence analysis of the cancer dose-response characteristics of 2,3,7,8-tetrachlorodibenzodioxin (TCDD). Toxicological Sciences 89 361-369.

Schlezinger JJ, Liu D, Farago M, Seldin DC, Belguise K, Sonenshein GE \& Sherr DH 2006 A role for the aryl hydrocarbon receptor in mammary gland tumorigenesis. Biological Chemistry 387 1175-1187.
Toledo RA, Lourenço DM Jr, Liberman B, Cunha-Neto MB, Cavalcanti MG, Moyses CB, Toledo SP \& Dahia PL 2007 Germline mutation in the aryl hydrocarbon receptor interacting protein gene in familial somatotropinoma. Journal of Clinical Endocrinology and Metabolism 92 1934-1937.

Vargiolu M, Fusco D, Kurelac I, Dirnberger D, Baumeister R, Morra I, Melcarne A, Rimondini R, Romeo G \& Bonora E 2009 The tyrosine kinase receptor RET interacts in vivo with AIP to alter survivin availability. Journal of Clinical Endocrinology and Metabolism 94 2571-2578.

Vierimaa O, Georgitsi M, Lehtonen R, Vahteristo P, Kokko A, Raitila A, Tuppurainen K, Ebeling TM, Salmela PI, Paschke R et al. 2006 Pituitary adenoma predisposition caused by germline mutations in the AIP gene. Science 312 1228-1230. 